
\title{
Outcome Improvement After Psychosocial Rehabilitation
}

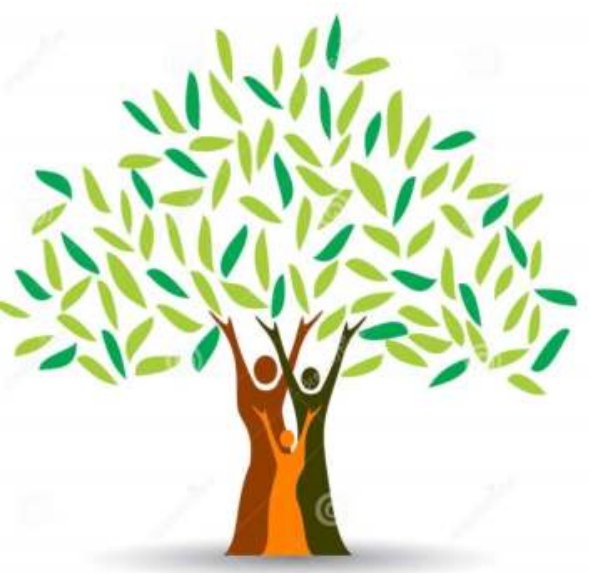

Alexandre Pértega-Gomes', Cristina Fragoeiro², João José Silva², Joaquim Ramos²

1 - Centro Hospitalar Universitário do Algarve

2 - Hospital Magalhães Lemos

hospital de

magalhães lemos, e.p.e.

\section{Introduction}

Psychosocial rehabilitation programmes play a central role in the recovery process of patients with severe mental disorders, promoting autonomy, community inclusion, and personal growth of patients formerly destined to institutionalisation. Despite their fundamental role in our current paradigm of Psychiatry, outcome measurement and validation of efficacy are ongoing challenges for many rehabilitation services, struggling with investment policies based on cost-effectiveness. Having worked in one of Portugal's first main psychosocial rehabilitation services, the authors conducted a retrospective cohort study of the patients admitted to Hospital Magalhães Lemos' Psychosocial Rehabilitation Service (PRS) from 2007 to 2016.

\section{Descriptive analysis}

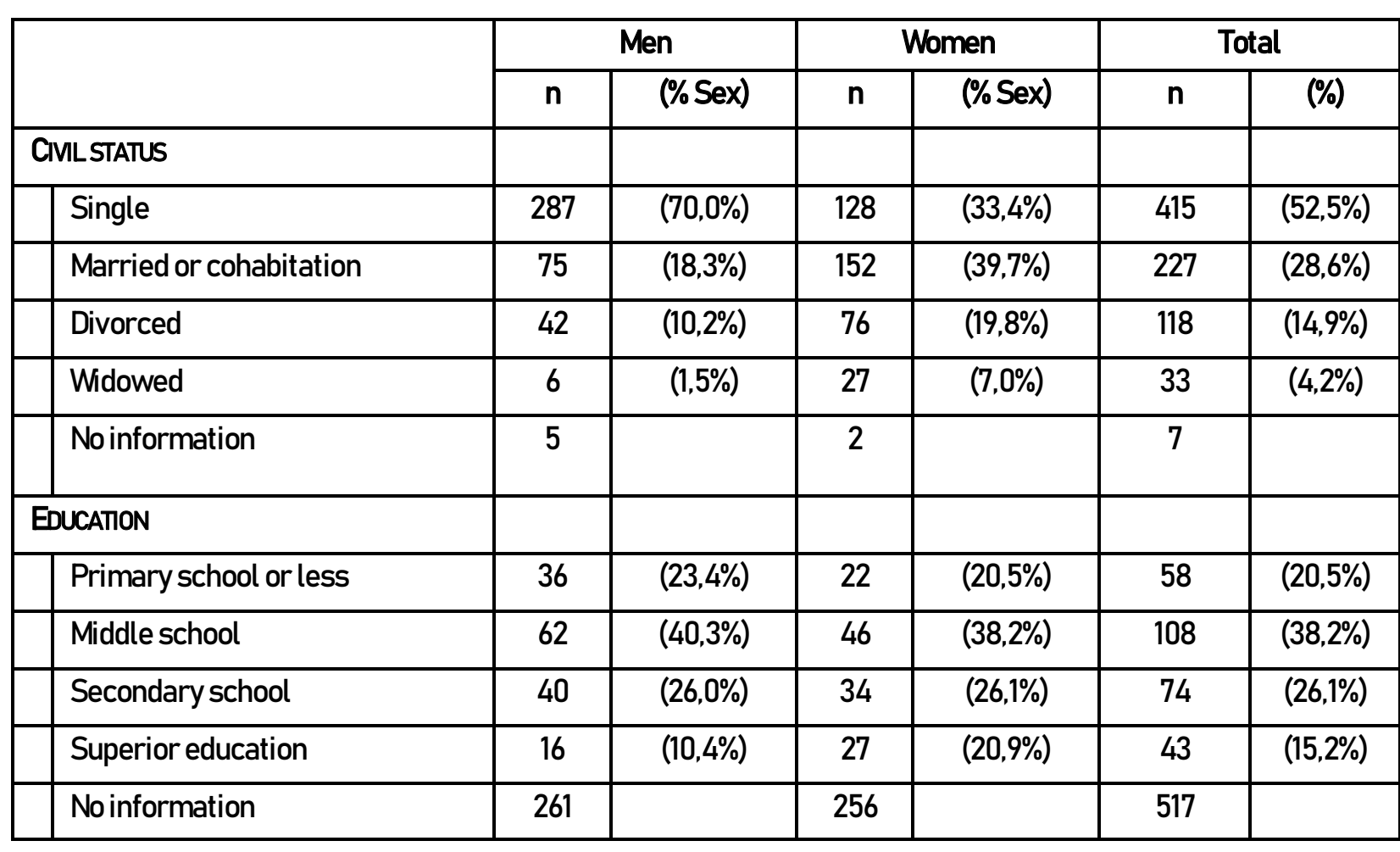

TABLE1. Sociodemographic characteristics of the patient cohort admitted to the PRS between January 2009 and December 2016.

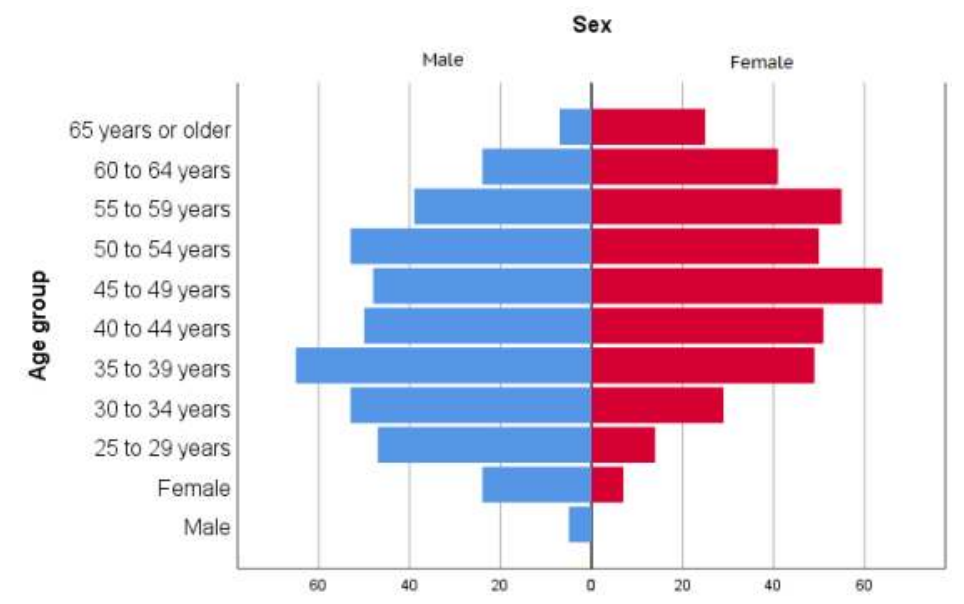

GRAPH1. Population pyramid of patients by age and sex.

\begin{tabular}{|l|c|c|c|c|c|c|}
\hline \multirow{2}{*}{} & \multicolumn{2}{|c|}{ Age at diagnosis } & \multicolumn{2}{c|}{ Age at admission } & \multicolumn{2}{c|}{ Time until referral } \\
\cline { 2 - 8 } & Median & (Range) & Median & (Range) & Median & (Range) \\
\hline $\begin{array}{l}\text { Adjustment and depressive } \\
\text { disorders }\end{array}$ & 49 & $41-56$ & 54 & $45-60$ & 4 & $1-8$ \\
\hline $\begin{array}{l}\text { Anxiety disorders and Obsessive- } \\
\text { compulsive disorder }\end{array}$ & 44 & $39-54$ & 48 & $44-57$ & 3 & $2,5-5,5$ \\
\hline Bipolar disorder & 48 & $39-54$ & 53 & $47-59$ & 5 & $2-8$ \\
\hline Schizoaffective disorder & 37 & $30-45$ & 44 & $36-51$ & 6 & $1-10$ \\
\hline $\begin{array}{l}\text { Schizophrenia, delusional disorder, } \\
\text { and other psychotic disorders }\end{array}$ & 33 & $26-42$ & 39 & $32-47$ & 7,5 & $2-10$ \\
\hline Addictive disorders & 43 & $26-51$ & 49 & $27-51$ & 4 & $1-8$ \\
\hline Personality disorders & 41 & $32-46$ & 46 & $38-53$ & 5 & $1-9$ \\
\hline Dementia and organic diseases & 38 & $23-55$ & 41 & $28-55$ & 2 & $1-5$ \\
\hline Intellectual disability & 28 & $21-34$ & 37 & $28-44$ & 1 & $0,5-3$ \\
\hline
\end{tabular}

TABLE2. Average age at diagnosis and at PRS admission for each group of diagnoses.

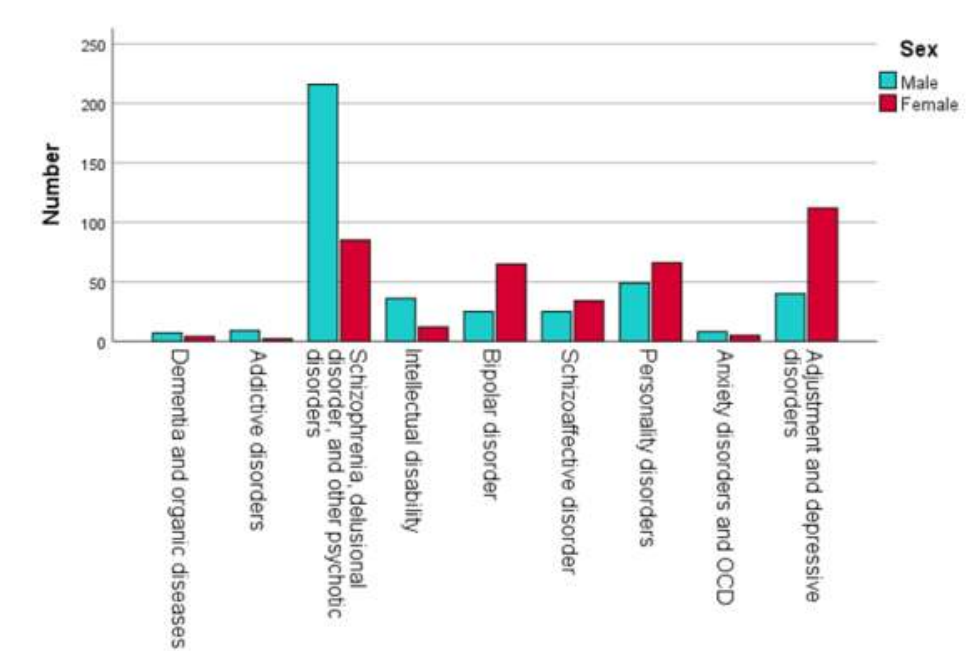

GRAPH2. Number and sex distribution of diagnoses in larger diagnostic groups.

\section{Statistical analysis}

\begin{tabular}{|c|c|c|c|c|c|c|}
\hline & \multicolumn{3}{|c|}{ No. hospitalisations/year } & \multicolumn{3}{|c|}{ Number of days hospitalised/100 } \\
\hline & $\begin{array}{l}\text { Median } \\
\text { before }\end{array}$ & $\begin{array}{c}\text { Median } \\
\text { after }\end{array}$ & $\begin{array}{l}P \text { Wil- } \\
\text { coxon }\end{array}$ & $\begin{array}{l}\text { Median } \\
\text { before }\end{array}$ & Median after & $\begin{array}{l}P \text { Wil- } \\
\text { coxon }\end{array}$ \\
\hline GLOBAL & 0,40 & 0,00 & $<0,001$ & 0,44 & 0,00 & $<0,001$ \\
\hline \multicolumn{7}{|l|}{ BY DIAGNOSTIC GROUP } \\
\hline $\begin{array}{l}\text { Dementia and organic diseas- } \\
\text { es }\end{array}$ & 0,00 & 0,00 & 0,496 & 0,55 & 0,24 & 0,500 \\
\hline Addictive disorders & 2,00 & 0,00 & 0,629 & 0,26 & 0,00 & 0,182 \\
\hline $\begin{array}{l}\text { Schizophrenia, delusional } \\
\text { disorder, and other psychotic } \\
\text { disorders }\end{array}$ & 0,60 & 0,00 & $<0,001$ & 0,55 & 0,00 & $<0,001$ \\
\hline Intellectual disability & 0,10 & 0,00 & 0,255 & 0,48 & 0,00 & 0,028 \\
\hline Bipolar disorder & 0,50 & 0,00 & $<0,001$ & 0,42 & 0,00 & $<0,001$ \\
\hline Schizoaffective disorder & 0,40 & 0,20 & 0,100 & 0,48 & 0,00 & 0,003 \\
\hline Personality disorders & 0,30 & 0,00 & 0,002 & 0,38 & 0,00 & $<0,001$ \\
\hline $\begin{array}{l}\text { Anxiety disorders and obses- } \\
\text { sive-compulsive disorder }\end{array}$ & 0,00 & 0,00 & 0,026 & 0,26 & 0,00 & 0,028 \\
\hline $\begin{array}{l}\text { Adjustment and depressive } \\
\text { disorders }\end{array}$ & 0,00 & 0,00 & $<0,001$ & 0,29 & 0,00 & $<0,001$ \\
\hline \multicolumn{7}{|l|}{ BYSEX } \\
\hline Male & 0,40 & 0,00 & $<0,001$ & 0,44 & 0,00 & $<0,001$ \\
\hline Female & 0,30 & 0,00 & $<0,001$ & 0,44 & 0,00 & $<0,001$ \\
\hline \multicolumn{7}{|l|}{ BYEDUCATON } \\
\hline Primary school or less & 0,50 & 0,16 & 0,004 & 0,39 & 0,00 & 0,002 \\
\hline Middle school & 0,80 & 0,21 & $<0,001$ & 0,55 & 0,00 & $<0,001$ \\
\hline Secondary school & 0,65 & 0,00 & $<0,001$ & 0,47 & 0,00 & $<0,001$ \\
\hline Superior education & 1,00 & 0,00 & 0,003 & 0,59 & 0,00 & $<0,001$ \\
\hline No information & 0,20 & 0,00 & $<0,001$ & 0,38 & 0,00 & $<0,001$ \\
\hline \multicolumn{7}{|l|}{ BY CIVL STATUS } \\
\hline Single & 0,50 & 0,00 & $<0,001$ & 0,51 & 0,00 & $<0,001$ \\
\hline $\begin{array}{l}\text { With marital/cohabitation } \\
\text { history }\end{array}$ & 0,30 & 0,00 & $<0,001$ & 0,38 & 0,00 & $<0,001$ \\
\hline
\end{tabular}

TABLE 3. Comparison of number of hospitalisations per year and number of days hospitalised divided by 100 before and after admission to the Psychosocial Rehabilitation Service.

\begin{tabular}{|l|l|l|}
\hline & B & $p$ \\
\hline Diagnostic group & & \\
\hline $\begin{array}{l}\text { Schizophrenia, delusional disorder, and other } \\
\text { psychotic disorders }\end{array}$ & $-0,005$ & 0,006 \\
\hline No. hospitalisations/year before PRS admission & $-2,080$ & $<0,001$ \\
\hline \multicolumn{2}{|l}{} \\
\hline Nagelkerke $\mathrm{R}^{2}=0,411$ & & \\
\hline
\end{tabular}

TABLE 4. Part of the bivariate logistic regression model considering number of hospitalisations after PRS admission as the dependent variable and larger diagnostic groups, age at PRS admission and number of hospitalisations per year before PRS admission as independent variables.

We conducted a bivariate logistic regression model considering the number of hospitalisations after PRS admission as the dependent variable (inferior versus superior) and larger diagnostic groups, age at PRS admission and number of hospitalisations per year before PRS admission as independent variables. Part of the results are shown in table 4. Fewer hospitalisations previous to PRS admittance and the diagnoses of schizophrenia, delusional disorder or other psychotic disorders are predictors of better PRS outcome in terms of number of hospitalisations after PRS admission.

\section{Conclusions}

We provide a brief summary of the results we obtained during data analysis. A total of 800 patients were admitted to the PRS between 2007 and 2016. A statistically significant reduction in number of hospitalisations per year, after stratifying for sex, age and civil status, was observed. By larger diagnostic groups, there was a statistically significant correlation with schizophrenia, delusional disorder, and other psychotic disorders, bipolar disorder, personality disorders, anxiety disorders, adjustment and depressive disorders. Though the number of hospitalisations was not significantly decreased, the duration of hospitalisations was in schizoaffective disorder and intellectual disability. These effects on hospitalisation outcomes are clear indirect measures of psychopathological stabilization. Fewer hospitalisations previous to PRS admittance and the diagnoses of schizophrenia, delusional disorder or other psychotic disorders are predictors of better PRS outcome in terms of number of hospitalisations after PRS admission. We hope to further develop and understand the PRS's outcomes, and intend to focus also on direct measures of social integration in the future. 